\title{
High-throughput sequencing of small RNAs and analysis of differentially expressed microRNAs associated with pistil development in Japanese apricot
}

\author{
Zhihong Gao ${ }^{* \dagger}$, Ting Shi ${ }^{\dagger}$, Xiaoyan Luo, Zhen Zhang, Weibing Zhuang and Liangju Wang
}

\begin{abstract}
Background: MicroRNAs (miRNAs) are a class of endogenous, small, non-coding RNAs that regulate gene expression by mediating gene silencing at transcriptional and post-transcriptional levels in high plants. However, the diversity of miRNAs and their roles in floral development in Japanese apricot (Prunus mume Sieb. et Zucc) remains largely unexplored. Imperfect flowers with pistil abortion seriously decrease production yields. To understand the role of miRNAs in pistil development, pistil development-related miRNAs were identified by Solexa sequencing in Japanese apricot.
\end{abstract}

Results: Solexa sequencing was used to identify and quantitatively profile small RNAs from perfect and imperfect flower buds of Japanese apricot. A total of 22,561,972 and 24,952,690 reads were sequenced from two small RNA libraries constructed from perfect and imperfect flower buds, respectively. Sixty-one known miRNAs, belonging to 24 families, were identified. Comparative profiling revealed that seven known miRNAs exhibited significant differential expression between perfect and imperfect flower buds. A total of 61 potentially novel miRNAs/new members of known miRNA families were also identified by the presence of mature miRNAs and corresponding miRNA*s in the sRNA libraries. Comparative analysis showed that six potentially novel miRNAs were differentially expressed between perfect and imperfect flower buds. Target predictions of the 13 differentially expressed miRNAs resulted in 212 target genes. Gene ontology (GO) annotation revealed that high-ranking miRNA target genes are those implicated in the developmental process, the regulation of transcription and response to stress.

Conclusions: This study represents the first comparative identification of miRNAomes between perfect and imperfect Japanese apricot flowers. Seven known miRNAs and six potentially novel miRNAs associated with pistil development were identified, using high-throughput sequencing of small RNAs. The findings, both computationally and experimentally, provide valuable information for further functional characterisation of miRNAs associated with pistil development in plants.

Keywords: Japanese apricot, microRNA, Pistil abortion, qRT-PCR, Solexa sequencing

\section{Background}

Japanese apricot (Prunus mume Sieb. et Zucc) is an important economic fruit crop in China and Japan, with more than 200 cultivars in China [1]. Japanese apricot fruit has consistently been one of the most valuable processing materials used in the food and wine-making

\footnotetext{
* Correspondence: gaozhihong@njau.edu.cn

${ }^{\dagger}$ Equal contributors

College of Horticulture, Nanjing Agricultural University, No 1 Weigang, Nanjing 210095, P. R. China
}

industries and is believed to contain many physiochemicals beneficial to human health. However, the phenomenon of imperfect flowers is common and seriously affects production yields. The percentage of imperfect flowers depends on the cultivar; the highest is $75.15 \%$ and the average is $35 \%$ [2]. Imperfect flowers are characterised by pistils below the stamens, withered pistils or the absence of pistils, and hence, they fail to bear fruit [3]. Several environmental factors and physiological processes have been 
shown to affect pistil development [1,4]. Previous research indicated that several miRNAs and multiple target genes are involved in flower development in model plants [5-12]. More recently, real-time quantitative reverse transcription polymerase chain reaction and in situ hybridisation showed that the PmAG mRNA was highlyexpressed in the sepals, carpels and stamens, and a weak signal was detected in the seeds and nutlets. No expressions were detected in the leaves or petals, but no significant differential was expressed between perfect and imperfect flowers [3]. Meanwhile, comparative proteomic analyses were performed on perfect and imperfect flowers, and several differently-expressed proteins were identified [13]. However, the type of molecular mechanism involved in pistil abortion remains unknown in Japanese apricot.

Small RNAs (sRNAs) are low molecular weight RNAs with regulatory functions. Based on differences in biogenesis and action, sRNAs are grouped into two categories: short interfering RNAs (siRNAs) and microRNAs (miRNAs) [14,15]. MicroRNAs are non-coding RNAs, 21-24 nucleotides (nt) long, which regulate gene expression at the post-transcriptional level [16-18]. In plants, miRNAs are processed from the stem-loop regions of long primary transcripts by a Dicer-like enzyme and are loaded into silencing complexes, where they generally direct the cleavage of complementary mRNAs [17]. Identified in plants less than 10 years ago $[19,20]$, miRNAs are already known to play numerous crucial roles at each major stage of development, typically at the cores of gene regulatory networks, targeting genes that are themselves regulators, such as those that encode transcription factors, suggesting that plant miRNAs are master regulators [18,21]. Among nontranscription factor targets, many miRNAs encode F-box proteins or ubiquitin-conjugating enzymes implicated in targeting selected proteins for proteasomal degradation, indicating miRNAs play a role in regulating protein stability and plant development $[22,23]$. miR156, miR163, miR169, miR172, miR398 and miR399 play important roles in flowering-time regulation and belong to ambient temperature-responsive miRNAs in plants $[9,24]$. miR172 has also acquired specialised species-specific functions in other aspects of plant development, such as cleistogamy and tuberisation [6].

The fact that a large number of the known miRNAs in the plant kingdom, from mosses and ferns to higher flowering plants, are evolutionarily conserved has been used as a practical indicator for the identification or prediction of miRNAs using homology searches in other species [25,26]. Recently developed, next-generation, high-throughput sequencing technologies provide a powerful tool for identifying, as well as quantifying,
miRNAs. These technologies open up the possibility of exploring sRNA populations in economically important species such as Arabidopsis thaliana [27,28], Oryza sativa [29,30], Populus trichocarpa [31,32], Vitis vinifera [33], Arachis hypogaea [34], Citrus sinensis [35], Citrus trifoliate [36], Medicago truncatula [37,38], Glycine max [39], Carthamus tinctorius, Cucumis sativus [40], Rehmannia glutinosa [41] and others. By means of highthroughput sequencing, miR164 and miR169 were shown to be drought-responsive miRNAs in Medicago truncatula [37]. miR167, miR1857 and miR172a are involved in the mutant trait formation of lycopene accumulation in sweet orange [35].

Although miRNAs have been extensively studied in the past, there has be no systematic examination of miRNAs performed on the Japanese apricot. To investigate the role of miRNAs on the pistil development of Japanese apricot, high-throughput sequencing technology (Solexa) was employed to survey sRNA populations from perfect and imperfect flower buds.

\section{Results}

\section{High-throughput sequencing of small RNAs from Japanese apricot flower bud tissue}

To identify miRNAs involved in the development of Japanese apricot flowers, Solexa sequencing was used on libraries of small RNAs from perfect and imperfect flower buds. A total of 22,561,972 and 24,952,690 reads were obtained from perfect and imperfect flower bud libraries, respectively, after filtering out those reads without small RNA sequences, ranging from 18 to $30 \mathrm{nt}$ in length (Figure 1), of which the majority were 19-25 nt long. The most abundant small RNAs in the perfect and imperfect libraries were $21 \mathrm{nt}$ and $24 \mathrm{nt}$ long, respectively. The distribution of $21 \mathrm{nt}$ small RNAs was approximately $28.35 \%$ and $32.31 \%$ in perfect and imperfect libraries, respectively, while the distribution of $24 \mathrm{nt}$ small RNAs was approximately $40.08 \%$ and $31.17 \%$ in the perfect and imperfect libraries, respectively. After removal of the adaptor, insert, poly(A) and short RNAs of $<18 \mathrm{nt}, 21,985,053$ and $24,239,332$ redundant clean reads were obtained from the perfect and imperfect flower buds, respectively, including rRNA, tRNA, snRNA, snoRNA, miRNA and several other unannotated reads (Tables 1 and 2). Of these clean reads, $11.76 \%$ (unique, $43.32 \%$ ) were perfect-specific, $10.88 \%$ (unique, $40.35 \%$ ) were imperfectspecific, and $77.36 \%$ (unique, $16.33 \%$ ) were present in both (Figure 2). The average number of common sequence frequency was 20.67, while that of libraryspecific reads was not more than 1.2 (Table 3). Among the sRNAs sequenced, unannotated redundant reads accounted for $77.83 \%$ and $74.25 \%$ for perfect and imperfect flower buds, respectively. 


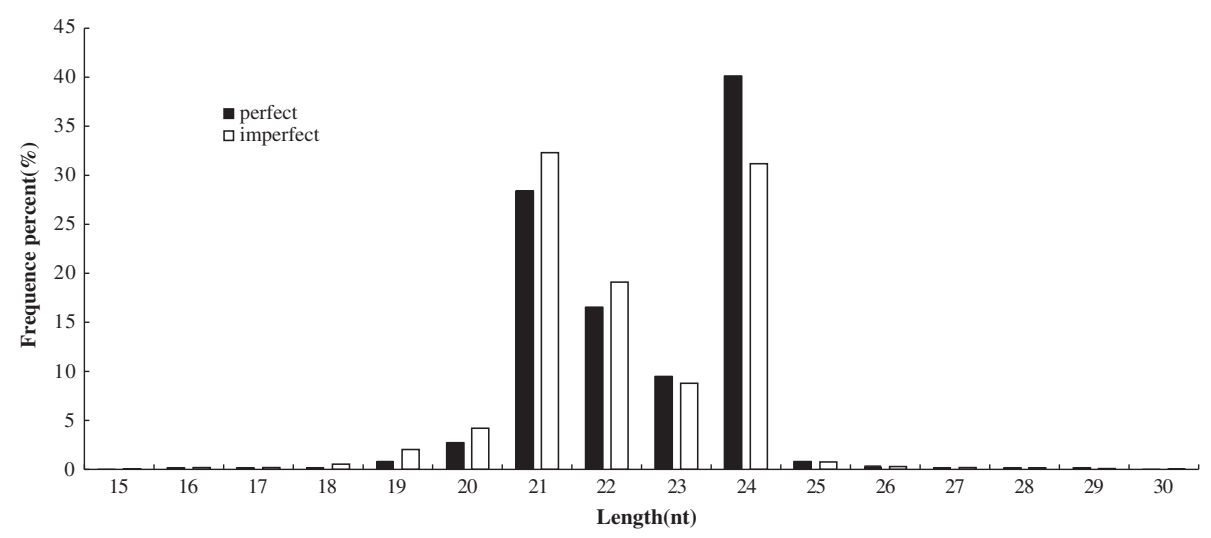

Figure 1 Length distribution of the small RNA library in Japanese apricot perfect and imperfect libraries.

\section{Identification of known miRNAs and evolutionary conservation}

To identify the known miRNAs, the sRNA library was BLASTN searched for known mature plant miRNAs in miRBase 17.0 (April 2011). Following the BLASTN searches and further sequence analysis, 61 unique sequences, belonging to 24 families, in the perfect and imperfect libraries were found to be orthologues of known miRNAs from other plant species, which had previously been deposited in the miRBase database (Table 4).

The number of members in differently-conserved miRNA families was analysed (Figure 3). A majority of the 24 miRNA families contained several members, and three families (miR156, miR159 and miR171) possessed multiple members, with 8,6 and 5 members, respectively. Nine miRNA families, namely miR160, miR168, miR394, miR403, miR408, miR535, miR827, miR828 and mir2111, had only one member.

The counts of reads for known miRNA families were also analysed, and it was found they indicated large divergences in expression frequency among these miRNAs. The number of reads for conserved miRNAs sequenced from the same, or different, miRNA families also varied drastically, with miR156, miR166 and

Table 1 Summary of data cleaning produced by small RNA sequencing (perfect and imperfect flower buds)

\begin{tabular}{cccccc}
\hline \multirow{2}{*}{ Type } & \multicolumn{2}{c}{ Perfect } & & \multicolumn{2}{c}{ Imperfect } \\
\cline { 2 - 3 } \cline { 5 - 6 } & Count & Percent (\%) & Count & Percent (\%) \\
\hline Total reads & $22,561,972$ & & $24,952,690$ & \\
High quality & $22,135,703$ & $100 \%$ & $24,466,679$ & $100 \%$ \\
3' adapter null & 53,592 & $0.24 \%$ & 49,464 & $0.20 \%$ \\
Insert null & 6,598 & $0.03 \%$ & & 8,281 & $0.03 \%$ \\
5' adapter contaminants & 36,203 & $0.16 \%$ & 58,925 & $0.24 \%$ \\
Smaller than 18nt & 48,147 & $0.22 \%$ & & 107,094 & $0.44 \%$ \\
Poly(A) & 6,110 & $0.03 \%$ & 3,583 & $0.01 \%$ \\
\hline
\end{tabular}

miR167 represented most frequently in the two libraries. Of these, miR156 was represented the most frequently, with 961,452 and 969,109 copies in the perfect and imperfect libraries, respectively. miR156, miR169, miR827 and miR828 were moderately abundant in the two libraries, while miR2111 was absent from the perfect library. It appeared, therefore, that the miRNA population present in the perfect library differed from that present in the imperfect library to some extent (Figure 4).

To investigate the evolutionary roles of these known miRNAs, extensive comparisons were performed against known miRNAs in other plant species, including Physcomitrella, Selaginella, Picea, Pinus, Arabidopsis, Brassica, Ricinus, Glycine, Medicago, Gossypium, Solanum, Aquilegia, Citrus, Populus, Vitis, Oryza, Sorghum and Zea (Figure 5). Among the miRNA sequences obtained from Japanese apricot, members in five of families (miR403, miR535, miR827, miR828 and miR2111) showed a lack of conservation of sequence identity compared to orthologues from 18 other plant species. Generally, Japanese apricot miRNAs had corresponding homologues in at least two plant species. Japanese apricot, Arabidopsis and Vitis vinifera shared 23 conserved miRNA families. Twelve (miR156, miR159, miR160, miR166, miR167, miR171, miR390, miR395, miR396, miR398, miR408 and miR535) out of 24 families had orthologues in Coniferophyta and Embryophyta, indicating that these 12 Japanese apricot miRNA families are ancient. Twelve (miR162, miR164, miR168, miR169, miR172, miR393, miR394, miR399, miR403, miR827, miR828 and miR2111) out of 24 families only had homologues in angiosperm, indicating that these 12 Japanese apricot miRNA families are recent. In addition, miR403, miR828 and miR2111 only had homologues in eudicotyledons, suggesting that these miRNAs are probably involved in the regulation of specific development, such as the development of embryos and cotyledons. 
Table 2 Distribution of small RNAs among different categories (perfect and imperfect flower buds)

\begin{tabular}{ccccc}
\hline Category & \multicolumn{2}{c}{ Perfec0074 } & \multicolumn{2}{c}{ Imperfect } \\
\cline { 2 - 3 } & Unique reads & Redundant reads & Unique reads & Redundant reads \\
\hline Total & $6,317,546(100 \%)$ & $21,985,053(100 \%)$ & $6,002,602(100 \%)$ & $24,239,332(100 \%)$ \\
rRNA & $55,021(0.87 \%)$ & $1,990,779(9.06 \%)$ & $63,243(1.05 \%)$ & $2,844,574(11.74 \%)$ \\
SnRNA & $4,443(0.07 \%)$ & $31,490(0.14 \%)$ & $5,145(0.09 \%)$ & $40,170(0.17 \%)$ \\
snoRNA & $1,376(0.02 \%)$ & $6,672(0.03 \%)$ & $1,445(0.02 \%)$ & $7,517(0.03 \%)$ \\
tRNA & $10,502(0.17 \%)$ & $364,461(1.66 \%)$ & $11,885(0.20 \%)$ & $698,413(2.88 \%)$ \\
miRNA & $26,734(0.42 \%)$ & $2,479,659(11.28 \%)$ & $30,931(0.52 \%)$ & $2,649,934(10.93 \%)$ \\
Unannotated & $6,219,470(98.45 \%)$ & $17,111,992(77.83 \%)$ & $5,889,953(98.12 \%)$ & $17,998,724(74.25 \%)$ \\
\hline
\end{tabular}

Identification of potentially novel miRNAs/new members of known miRNA families and nucleotide bias

The Mireap prediction software developed by the Beijing Genomics Institute (Shenzhen, China) was used to identify potentially novel miRNAs and new members of known miRNA families by exploring the secondary structure based upon a trans-species alignment of apricot small RNA data against the peach (Prunus persica) genome. After removal of the conserved miRNAs, sequences were aligned with the peach genome sequence. A total of 405 and 423 miRNA candidates were obtained from the perfect and imperfect flower bud libraries, respectively. The prediction of potentially novel miRNA/new members of known miRNA families candidates was summarised, including the base bias on the first position among small RNA candidates of certain lengths. Based on this summary, prediction accuracy could be assessed according to the base bias of known miRNAs. The majority of these novel miRNA candidates had lengths of 21 and $22 \mathrm{nt}$, and started with a $5^{\prime} \mathrm{U}$ (Figure 6A and $\mathrm{B}$ ).

Among the miRNA candidates, 61 were identified with complementary miRNA*s (fold-back structures in Additional files 1 and 2), indicating that these candidate miRNAs were most likely new in Japanese apricot, and several potentially novel ones may be unique to Japanese apricot or Prunus plants. The counts of several miRNA*s of these potentially novel miRNAs were low (Table 5). Nevertheless, no requirement for counts of miRNA*s was given in the most recent criteria for the annotation of plant miRNAs [42]. Therefore, these miRNAs were still considered to be potentially new. Candidate miRNAs with only one miRNA* have been identified as new miRNAs in rice and leguminous plants. The minimum free energy (MFE) for the hairpin structures of miRNA precursors was lower than $-18 \mathrm{kcal} / \mathrm{mol}$, and the length of new miRNA precursors ranged from $74 \mathrm{nt}$ to $377 \mathrm{nt}$ (Table 5).

\section{Differentially expressed miRNAs between perfect and imperfect flower bud libraries}

Small RNAs in the perfect and imperfect libraries were enriched for lengths of 21-24 nt (Figure 1), a typical range for plant miRNAs. For small RNAs shorter than $23 \mathrm{nt}$, the imperfect flower buds had higher expression levels than the perfect flower buds, while for small RNAs longer than $23 \mathrm{nt}$, the opposite was the case. In addition to the different length distributions of small RNAs, the proportions of each type of small RNA in the two libraries were also different (Table 2). The proportion of miRNAs in perfect flower buds was higher than that in imperfect flower buds. However, rRNAs, snRNAs and tRNAs in imperfect flower buds were higher than in perfect flower buds. In summary, the small RNA transcriptomes of the two libraries exhibited certain differences with respect to length distribution and composition.

In order to identify miRNAs related to pistil development, the normalised expressions of miRNAs in the perfect and imperfect small RNA libraries were compared. The miRNAs with changes in expression levels greater than 1.5 -fold and $p$-values less than 0.05 are presented in Table 6. The results from high-throughput sequencing
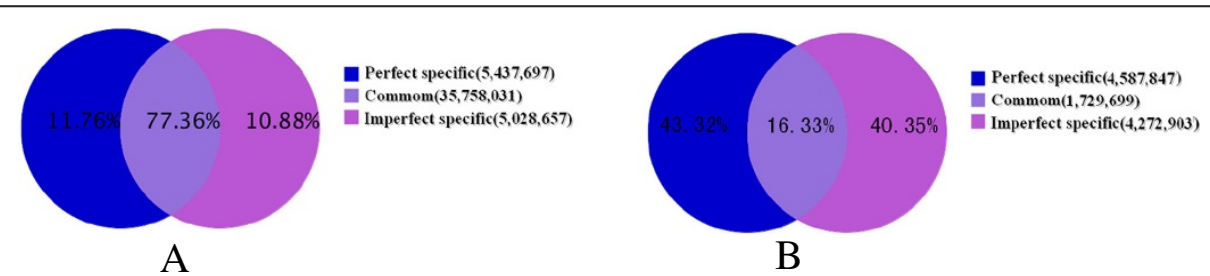

Figure 2 Summary of common and specific sequences between perfect and imperfect libraries. (A)Total sRNAs and (B)Unique sRNAs. 
Table 3 Small RNA sequences and mean frequencies in both perfect and imperfect libraries

\begin{tabular}{cccc}
\hline Class & Unique sRNAs & Total sRNAs & Mean frequency \\
\hline Total sRNAs & 10590449 & 46224385 & 4.36 \\
Perfect and imperfect common & 1729699 & 35758031 & 20.67 \\
Perfect specific & 4587847 & 5437697 & 1.19 \\
Imperfect specific & 4272903 & 5028657 & 1.18 \\
\hline
\end{tabular}

showed that seven known miRNAs and six potentially novel miRNAs/new members of known miRNA families were relevant to pistil development (Table 6). Of these 13 sequences, nine demonstrated a greater than threefold change in expression levels between the perfect and imperfect libraries. Among the six differentially expressed potentially novel miRNAs/new members of known miRNA families, miR6274 and miR482c were perfect specific, while miR6295, mi171d and miR319b were imperfect specific. Three miRNAs were downregulated, and ten miRNAs were up-regulated in pistil abortion (Table 6).

To confirm the differential expression of the miRNAs, the expressions of four of the seven known miRNA genes and five of the six novel miRNA genes were analysed using poly(A) qRT-PCR. The expression level of each gene in the perfect and imperfect flower buds was compared with its abundance in the sequencing data of the sRNA library. The results indicated that nine miRNAs had the same expression patterns in the perfect and imperfect flower buds as those in the sequencing data (Figure 7).

\section{Prediction of potential targets of differentially expressed miRNAs}

An indication of the genes responsible for pistil abortion was sought by the inspection of 212 potential targets of the 13 differentially expressed miRNAs (Additional file $3)$. There are three ontologies in Gene Ontology (GO): molecular functions, cellular components and biological processes. GO categories were assigned to all 212 putative targets, according to their cellular components, molecular functions and biological processes (Figure 8). On the basis of molecular function, the genes were finally classified into 10 categories, as shown in Figure 8B. The top three over-represented GO terms are enzyme activity, nucleic acid binding and other binding. Thirteen biological processes were identified, with the three most frequent being developmental process, regulation of transcription and response to stress (Figure 8C).

The high frequency of 'regulation of transcription' and 'response to stress' terms are easily explainable, since miRNAs are involved in diverse regulatory events [43]. Moreover, many flower developmental genes were also predicted targets of miRNAs. One gene involved in ovule development was further analysed (miR319,
miR319a and miR319e and putative target auxin response factor 2 (ARF2) [Ppa022314m]). The results implied the possible roles of miRNAs in the regulation of biological processes involved in pistil abortion.

\section{Discussion}

\section{High-throughput sequencing of Japanese apricot small RNAs}

Most conserved miRNAs in plants have been identified by traditional Sanger sequencing or computational approaches [43-47]. However, a large number of nonconserved or species-specific miRNAs in plants usually accumulate at a lower level than conserved miRNAs, and are typically not easily revealed using traditional sequencing methods [48]. Therefore, the construction and high-throughput sequencing of small RNA libraries seems to be the most efficient method for miRNA identification $[36,49]$. The aim of this work was to identify the evolutionary known and potentially novel Japanese apricot-specific miRNAs recovered from perfect and imperfect flower bud libraries, and to analyse the differentially expressed miRNAs associated with pistil development. In our study, small RNA libraries of Japanese apricot from the Solexa platform, one of the newlydeveloped high-throughput sequencing technologies, generated shorter reads (up to $35 \mathrm{bp}$ ) but yielded 1-3 million reads per sample. This method has been most popularly employed to discover miRNAs in various organisms. As expected, a large number of reads were generated by our small RNA libraries, of which 61 are known to belong to 24 families. In addition, 61 potentially novel miRNAs/new members of known miRNA families were identified in Japanese apricot.

Taking a broader view of the high-throughput sequencing of small RNAs in Japanese apricot, it was observed that small RNAs of $24 \mathrm{nt}$ dominated the library of unique species, as has been reported for many other plant species, such as Arabidopsis thaliana [28], Citrus trifoliata [36], Medicago truncatula [37,38], Citrus sativus [50] and Citrus Sinensis [51]. However, the most abundant small RNAs in the imperfect library were 21 nt long. Normally, the length of small RNAs is between $18 \mathrm{nt}$ and $30 \mathrm{nt}$. Length distribution analysis is a helpful way to assess the composition of small RNA samples. For example, miRNA is normally 21 nt or 22 nt long, whereas siRNA is $24 \mathrm{nt}$ long [52]. The data obtained 
Table 4 Known miRNAs in perfect and imperfect libraries

\begin{tabular}{|c|c|c|c|c|c|}
\hline \multirow[t]{2}{*}{ Family } & \multirow[t]{2}{*}{ miRNA name } & \multicolumn{2}{|c|}{ Perfect } & \multicolumn{2}{|c|}{ Imperfect } \\
\hline & & Counts & Normalised & Counts & Normalised \\
\hline \multirow[t]{8}{*}{ MIR156 } & miR156a & 45352 & 2062.86 & 61361 & 2531.46 \\
\hline & miR156b & 26572 & 1208.64 & 29886 & 1232.95 \\
\hline & miR156c & 145205 & 6604.71 & 210543 & 8686.01 \\
\hline & miR156f & 118 & 5.37 & 188 & 7.76 \\
\hline & miR156h & 0 & 0.01 & 4 & 0.17 \\
\hline & miR156k & 25 & 1.14 & 46 & 1.90 \\
\hline & miR157a & 735314 & 33446.09 & 658343 & 27160.11 \\
\hline & miR157d & 8866 & 403.27 & 8738 & 360.49 \\
\hline \multirow[t]{6}{*}{ MIR159 } & miR159a & 18682 & 849.76 & 38726 & 1597.65 \\
\hline & miR319 & 21 & 0.96 & 171 & 7.05 \\
\hline & miR319a & 121 & 5.50 & 1172 & 48.35 \\
\hline & miR319c & 6 & 0.27 & 7 & 0.29 \\
\hline & miR319e & 1 & 0.05 & 40 & 1.65 \\
\hline & miR319g & 0 & 0.01 & 5 & 0.21 \\
\hline MIR160 & miR160a & 110 & 5.00 & 808 & 33.33 \\
\hline \multirow[t]{2}{*}{ MIR162 } & miR162 & 1 & 0.05 & 4 & 0.17 \\
\hline & miR162a & 718 & 32.66 & 617 & 25.45 \\
\hline \multirow[t]{2}{*}{ MIR164 } & miR164a & 6256 & 284.56 & 4134 & 170.55 \\
\hline & miR164f & 63 & 2.87 & 52 & 2.15 \\
\hline \multirow[t]{3}{*}{ MIR166 } & miR166 & 60 & 2.73 & 85 & 3.51 \\
\hline & miR166a & 222689 & 10129.11 & 281639 & 11619.09 \\
\hline & miR166h & 1369 & 62.27 & 2013 & 83.05 \\
\hline \multirow[t]{4}{*}{ MIR167 } & miR167-3p & 810 & 36.84 & 691 & 28.51 \\
\hline & miR167a & 151440 & 6888.32 & 127360 & 5254.27 \\
\hline & miR167d & 52161 & 2372.57 & 45113 & 1861.15 \\
\hline & miR167f & 61643 & 2803.86 & 44482 & 1835.12 \\
\hline MIR168 & miR168a & 64099 & 2915.57 & 82261 & 3393.70 \\
\hline \multirow[t]{4}{*}{ MIR169 } & miR169b & 510 & 23.20 & 538 & 22.20 \\
\hline & miR169e & 10 & 0.45 & 6 & 0.25 \\
\hline & miR169g & 11 & 0.50 & 1 & 0.04 \\
\hline & miR169h & 18 & 0.82 & 10 & 0.41 \\
\hline \multirow[t]{6}{*}{ MIR171 } & miR171 & 483 & 21.97 & 630 & 25.99 \\
\hline & miR171b & 1578 & 71.78 & 1994 & 82.26 \\
\hline & miR171d & 1 & 0.05 & 0 & 0.01 \\
\hline & miR171f & 13 & 0.59 & 15 & 0.62 \\
\hline & miR171b-3p & 2195 & 99.84 & 2831 & 116.79 \\
\hline & miR171I & 4 & 0.18 & 9 & 0.37 \\
\hline \multirow[t]{4}{*}{ MIR172 } & miR172a & 13173 & 599.18 & 10393 & 428.77 \\
\hline & miR172b & 5 & 0.23 & 0 & 0.01 \\
\hline & miR172e & 181 & 8.23 & 181 & 7.47 \\
\hline & miR172g & 123 & 5.59 & 102 & 4.21 \\
\hline MIR2111 & miR2111a & 0 & 0.01 & 5 & 0.21 \\
\hline MIR390 & miR390a & 18872 & 858.40 & 32445 & 1338.53 \\
\hline
\end{tabular}

Table 4 Known miRNAs in perfect and imperfect libraries (Continued)

\begin{tabular}{|c|c|c|c|c|c|}
\hline & miR390a-3p & 602 & 27.38 & 1207 & 49.80 \\
\hline \multirow[t]{3}{*}{ MIR393 } & miR393 & 221 & 10.05 & 603 & 24.88 \\
\hline & miR393a & 2 & 0.09 & 77 & 3.18 \\
\hline & miR393b & 4 & 0.18 & 3 & 0.12 \\
\hline MIR394 & miR394a & 24 & 1.09 & 301 & 12.42 \\
\hline \multirow[t]{2}{*}{ MIR395 } & miR395a & 14 & 0.64 & 94 & 3.88 \\
\hline & miR395b & 1 & 0.05 & 2 & 0.08 \\
\hline \multirow[t]{2}{*}{ MIR396 } & miR396a & 2046 & 93.06 & 3149 & 129.91 \\
\hline & miR396b & 869 & 39.53 & 1194 & 49.26 \\
\hline \multirow[t]{3}{*}{ MIR398 } & miR398 & 0 & 0.01 & 1 & 0.04 \\
\hline & miR398a & 13 & 0.59 & 16 & 0.66 \\
\hline & miR398b & 7 & 0.32 & 12 & 0.50 \\
\hline \multirow[t]{2}{*}{ MIR399 } & miR399a & 0 & 0.01 & 7 & 0.29 \\
\hline & miR399f & 29 & 1.32 & 45 & 1.86 \\
\hline MIR403 & miR403 & 325 & 14.78 & 510 & 21.04 \\
\hline MIR408 & miR408 & 19 & 0.86 & 14 & 0.58 \\
\hline MIR535 & miR535a & 9743 & 443.16 & 12158 & 501.58 \\
\hline MIR827 & miR827a & 22512 & 1023.97 & 21786 & 898.79 \\
\hline MIR828 & miR828a & 48 & 2.18 & 48 & 1.98 \\
\hline
\end{tabular}

here imply that the most abundant small RNAs are miRNAs and siRNAs in perfect and imperfect flower buds, respectively.

The overall distribution pattern of small RNAs (21 nt sRNAs $=30.33 \%$, and 24 nt sRNAs $=35.63 \%)$ in Japanese apricot is significantly different from that in Pinus contorta, a conifer species in which 21 nt RNAs are more abundant $(>50 \%)$ and $24 \mathrm{nt}$ RNAs are less frequent (2.5\%). A striking difference also exists when comparing Japanese apricot small RNAs with monocot species of rice. When compared with eudicotyledon species of sweet orange, the difference is not as noticeable, but still exists, such that $24 \mathrm{nt}$ sRNAs are most frequent $(>50 \%)$ while 21 nt sRNAs are less common $(<20 \%)$. These analyses indicate that the small RNA transcriptome is complicated across plant species and can be significantly different between phylogenetically distant plant families.

\section{miRNAs identified in plant flowers}

Arabidopsis miRNAs [27] regulate multiple developmental events. In the past, miRNA identification in flowers using sequencing approaches has been common, and has been applied in the study of Arabidopsis [53], tomato [54], orchid [24], Boechera [12], maize [55], cotton [49], safflower and grape [56,57]. In this study, high-throughput sequencing of extracts from Japanese apricot flower buds led to the identification of 61 known miRNAs, belonging to 24 families, and 


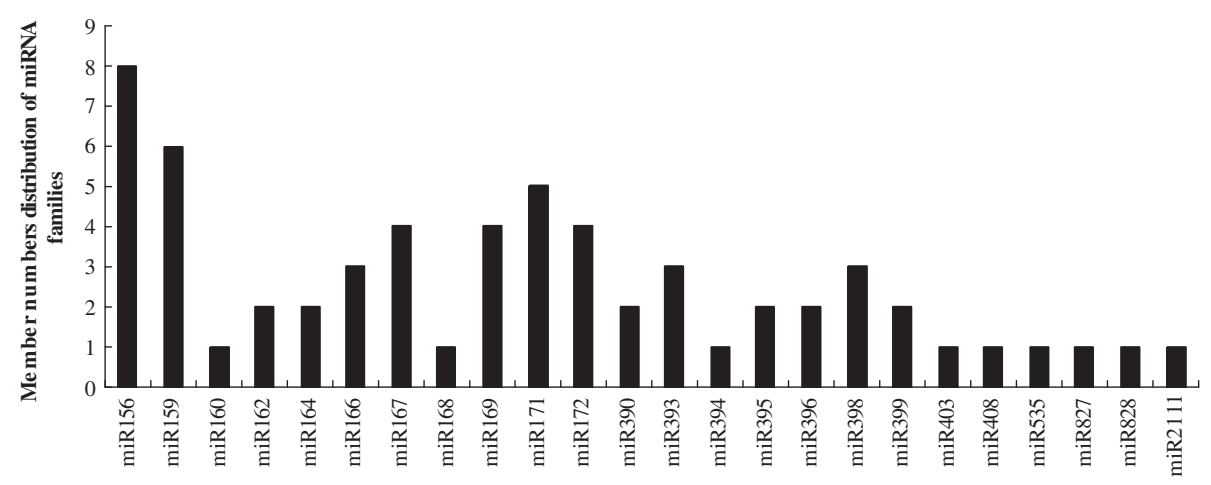

Figure 3 Member numbers of identified miRNAs in each conserved miRNA family in Japanese apricot.

61 potentially novel miRNAs/new members of known miRNA families. Analysis of these revealed that some miRNA families are expressed in the flowers of other plant species, but they are not flower-specific. miR156/ miR157, miR166 and miR167 were represented most frequently in the libraries in this study. The involvement of three miRNA families (miR172, miR159/ miR319 and miR156) in flowering-time regulation has been recently demonstrated in other investigations [22]. miR164, miR319, miR159 and miR167 specify particular cell types during the later stages of flower development [7]. Furthermore, the comparison of these species' miRNAs showed that miR156/miR157 and miR172 may be components of a regulatory pathway mediating the transition between the vegetative and reproductive phases in plants. In addition, miR172 regulates stem cell fate and defines the inner boundary of APETALA3 and pistillata expression domains in Arabidopsis floral meristems [58]. By targeting APETALA2 and type III homeodomain-leucine zipper (HD-Zip) genes, miR166 regulates the temporal program of floral stem cells [59]. It is believed that miR167, like miR160, targets mRNAs coding for ARF, which are DNA-binding proteins that are thought to control transcription in response to the phytohormone auxin $[27,60]$. Transcriptional regulation is important for many of the diverse developmental responses to auxin signals, which include cell elongation, division and differentiation in both roots and shoots [61].

\section{miRNAs possibly involved in the regulation of pistil} abortion in imperfect Japanese apricot flower buds The characterisation and comparative profiling of entire sets of small RNAs (small RNA transcriptome), especially miRNAs, provides the foundation for unraveling the complex miRNA-mediated regulatory networks controlling pistil abortion in imperfect Japanese apricot flower buds. In this study, a number of miRNAs were shown to be differentially expressed between perfect and imperfect flower buds. Compared with the perfect library, four known miRNA genes and three potentially novel miRNA/new members of known miRNA families genes were expressed exclusively in imperfect flower buds. On the other hand, it was found that two potentially novel miRNAs/new members of known miRNA families were perfect-specific. Moreover, a total of seven known miRNAs and six potentially novel miRNAs

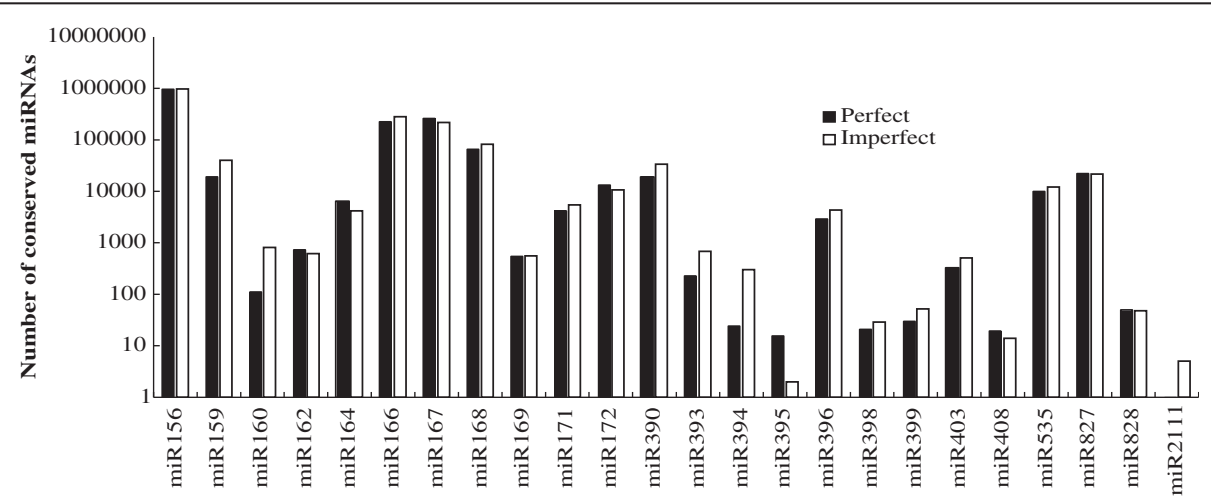

Figure 4 Counts of identified miRNAs in each conserved miRNA family in Japanese apricot. 


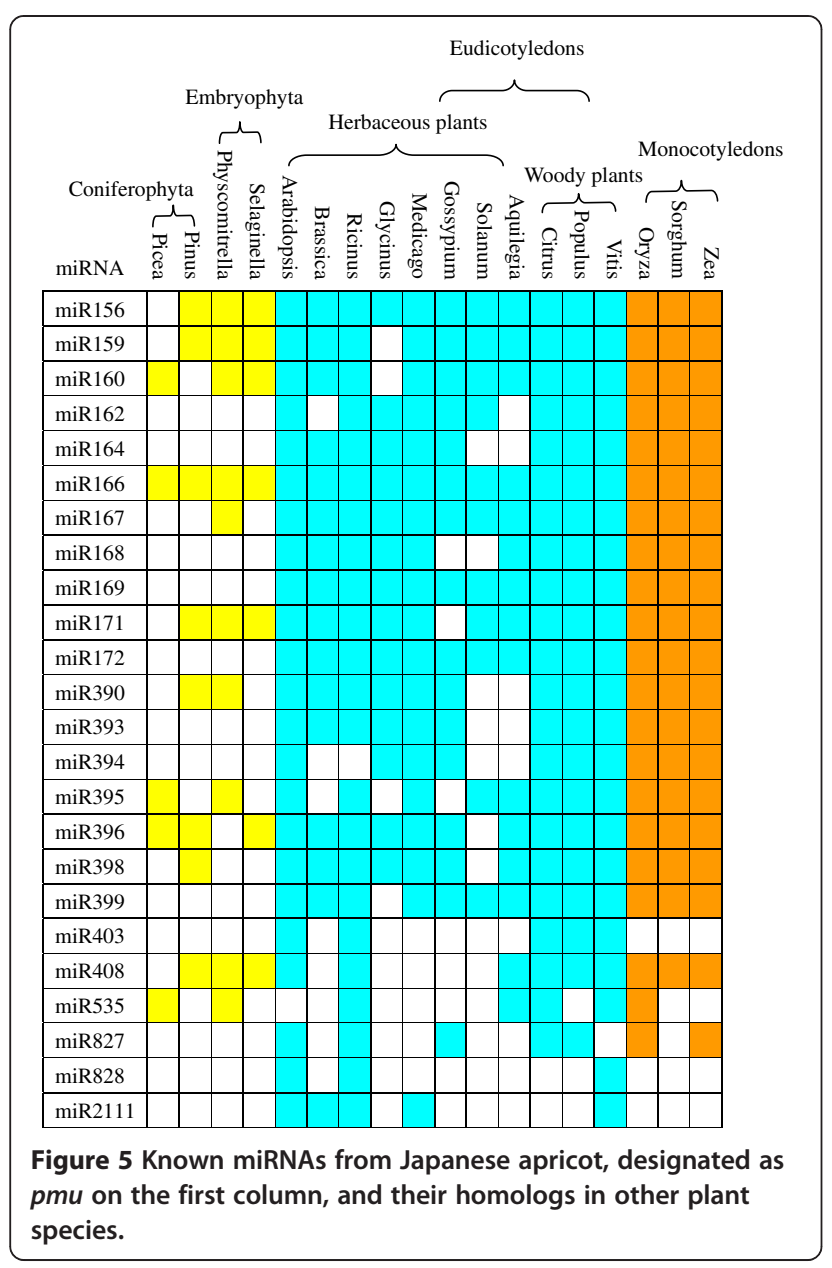

exhibited significant expression changes between the perfect and imperfect libraries.

The relationship between the sRNA genes and the miRNA target genes is one of the hot spots in the phenomenon of 'miRNA-associated transitivity'. Target prediction of these differential miRNAs could provide information on the biological processes regulated by miRNA. The annotations of these potential miRNA target genes provided an alternate view of gene regulation of the pistil abortion trait formation in imperfect flower buds. It was discovered that these groups of predicted miRNA-target genes are possibly involved in the pistil abortion trait formation.

The majority of genes encoding transcription factors or F-box proteins have a significant role in the plant development $[44,62]$. In the present study, it was found that the predicted targets of miR319, miR319a, miR319e, miR160, miR393, miR394, miR6274, miR6295 and miR171d were either transcription factors or F-box proteins. In addition, it is predicted that $\mathrm{miR} 319 / \mathrm{miR} 319 \mathrm{a} /$ miR319e target $A R F 2$ genes and that miR160a targets $A R F 16 / 17$. Auxin regulates a variety of physiological and developmental processes in plants. ARF has been reported to regulate flower and leaf development $[8,63,64]$. ARF2 is a transcriptional suppressor that has been found to be involved in ethylene, auxin, ABA and brassinosteroid pathways, in order to control the onset of leaf senescence, floral organ abscission and ovule development [64]. ARF2 promotes transitions between multiple stages of Arabidopsis development and positively regulates flower development [65]. In this study, the expression of $\mathrm{miR} 319 / \mathrm{miR} 319 \mathrm{a} / \mathrm{miR} 319 \mathrm{e}$ was shown to be higher in imperfect than in perfect flower buds. Consequently, the expression of ARF2 was repressed by these miRNAs and thus regulated pistil development. Moreover, TCP2 (TEOSINTE BRANCHED/CYCLOIDEA/ $P C F)$ transcription factor genes and MYB33, which belong to a GAMYB-like family of transcription factors, are also targets of miR319/miR319a/miR319e in our prediction, which agrees with previous reports $[10,66]$. Therefore, it is conceivable that the over-expression of miR319/miR319a/ miR319e may contribute to an increase in imperfect flower ratios in pistil development.

\section{Conclusions}

The present study first comparatively constructed the miRNAomes between perfect and imperfect Japanese apricot flowers and identified 61 known miRNAs belonging to 24 families. Comparative profiling revealed that seven known miRNAs exhibited significant expression differences between perfect and imperfect flower

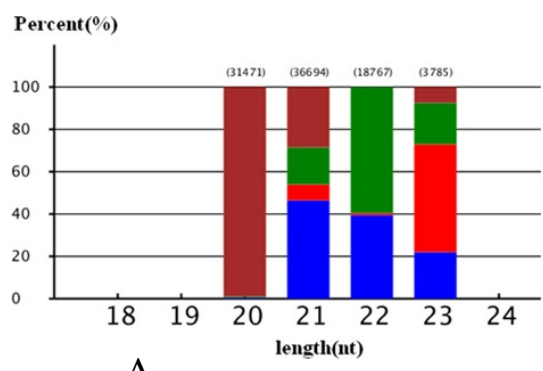

A

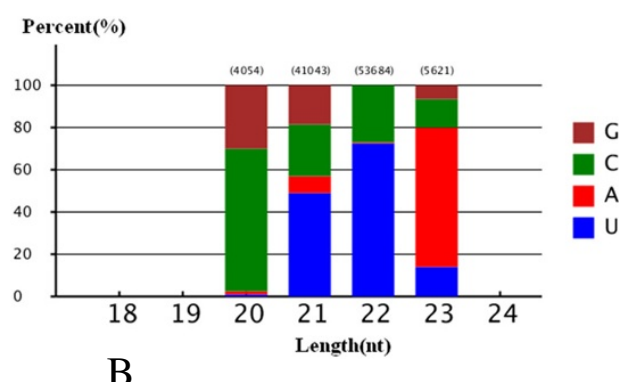

B

Figure 6 Novel miRNA candidates first nucleotide bias in Japanese apricot. (A) Perfect library and (B) Imperfect library. 
Table 5 Novel miRNAs/new members of known miRNA families in perfect and imperfect libraries

\begin{tabular}{|c|c|c|c|c|c|c|c|}
\hline miRNA & $\begin{array}{l}\text { Length of } \\
\text { mature(nt) }\end{array}$ & Sequence $\left(5^{\prime}-3^{\prime}\right)$ & $\begin{array}{c}\text { Counts of } \\
\text { miRNAs/miRNA*s }\end{array}$ & Location & $\begin{array}{c}\text { Length of } \\
\text { precursors(nt) }\end{array}$ & Arm & $\begin{array}{c}\text { MFE } \\
\text { (kcal/mol) }\end{array}$ \\
\hline miR6257 & 21 & TCTTAACTGTTGGATTAGGCT & $22 / 1$ & scaffold_10:708566:708677:- & 112 & $5^{\prime}$ & -26.7 \\
\hline miR6258 & 21 & TTCCAGCTGTAAAGATCAAGA & $5 / 5$ & scaffold_1:230373:230544:+ & 172 & $5^{\prime}$ & -88.7 \\
\hline miR6259 & 21 & TAGAAAAATACGGGCGATAAA & $6 / 1$ & scaffold_1:37406755:37406880:+ & 126 & $3^{\prime}$ & -53.6 \\
\hline miR6260 & 21 & TGGAGTGAGAGAATGGGAGGT & $14 / 2$ & scaffold_1:40569695:40569796:+ & 102 & $3^{\prime}$ & -50.4 \\
\hline miR6261 & 22 & AAGTGATTATATGGAGAAGCAC & $13 / 1$ & scaffold_1:46392103:46392176:+ & 74 & $3^{\prime}$ & -26.5 \\
\hline miR6262 & 21 & TCTITAGAAAGTTAGAATTGT & $5 / 1$ & scaffold_1:23904565:23904750:-- & 186 & $5^{\prime}$ & -67 \\
\hline miR6263 & 21 & AAGTGGACAAAAGGGGAGTGG & $16 / 2$ & scaffold_2:16774627:16774733:+ & 107 & $3^{\prime}$ & -24.9 \\
\hline miR6264 & 21 & ATGCCTATGGACACGTGTCAA & $6 / 1$ & scaffold_2:10473541:10473644:- & 104 & $3^{\prime}$ & -56.02 \\
\hline miR6265 & 23 & TTGAACTITGACCCGATTCGCAT & $15 / 1$ & scaffold_3:13798983:13799084:+ & 102 & $5^{\prime}$ & -36.77 \\
\hline miR6266a & 21 & TAAATGCAGGGGCAAAATGAT & $149 / 4$ & scaffold_4:6953607:6953883:+ & 277 & $5^{\prime}$ & -69.81 \\
\hline miR6266b & 21 & TAAATGCAGGGGCAAAATGAT & $109 / 2$ & scaffold_4:8221370:8221603:+ & 234 & $5^{\prime}$ & -60.63 \\
\hline miR6266c & 21 & TAAATGCAGGGGCAAAATGAT & $106 / 1$ & scaffold_7:12665062:12665327:- & 266 & $5^{\prime}$ & -59.43 \\
\hline miR6267a & 21 & TAGAGAGGTGGTACAATTGTG & $45 / 1$ & scaffold_4:9720663:9720766:+ & 104 & $3^{\prime}$ & -69.6 \\
\hline miR6267b & 21 & ATTAGAGAGGCGGTAAACAAT & $5 / 1$ & scaffold_4:13686619:13686731:- & 113 & $3^{\prime}$ & -35.9 \\
\hline miR6268 & 21 & TGAGGAGATGGAGAGTAGATA & $244 / 3$ & scaffold_4:16645739:16645874:+ & 136 & $5^{\prime}$ & -77.7 \\
\hline miR6269 & 21 & TGTGAATAGTGATTGCCATGG & $18 / 5$ & scaffold_4:20136895:20136989:+ & 95 & $5^{\prime}$ & -36.7 \\
\hline miR6270 & 21 & TTCTGGTATTGGAATTTCATT & $259 / 26$ & scaffold_4:30105651:30106027:+ & 377 & $3^{\prime}$ & -117.7 \\
\hline miR6271 & 21 & TCAAGATTGAGAGATATAATG & $24 / 3$ & scaffold_4:8916468:8916590:- & 123 & $3^{\prime}$ & -34.3 \\
\hline miR6272 & 21 & TAGCTGTAAATGAGTGTTITT & $5 / 1$ & scaffold_4:19289821:19289925:- & 105 & $5^{\prime}$ & -25.8 \\
\hline $\operatorname{miR6273}$ & 21 & AATGCAGCATGATITIITITा & $81 / 63$ & scaffold_5:3421010:3421132:+ & 123 & $3^{\prime}$ & -42.2 \\
\hline miR6274 & 23 & TATTITGCTATCTTCGGGCAATA & $15 / 2$ & scaffold_5:3414706:3414834:- & 129 & $5^{\prime}$ & -35.8 \\
\hline miR6275 & 22 & AGTGGAAGTAGCAAGGGGAAGC & $14 / 1$ & scaffold_5:10005396:10005502:- & 107 & $3^{\prime}$ & -67.6 \\
\hline $\operatorname{miR} 6276$ & 21 & AAAGGCTCATACAAATATTCC & $14 / 3$ & scaffold_6:8093383:8093491:- & 109 & $5^{\prime}$ & -21.7 \\
\hline miR6277 & 21 & TGTGTGTGGAAAGAGCGAGAC & $1661 / 5$ & scaffold_6:28212589:28212684:- & 96 & $3^{\prime}$ & -47.16 \\
\hline miR6278 & 22 & TGAACCTTGTGTACAAATTGGC & $16 / 3$ & scaffold_7:7789275:7789372:+ & 98 & $3^{\prime}$ & -41.9 \\
\hline miR6279 & 21 & TAGACAAGAATTCCAGAGACC & $9 / 1$ & scaffold_7:16179849:16180001:+ & 153 & $3^{\prime}$ & -31.4 \\
\hline miR6280 & 21 & TTGGCAGTAAGATTITTGGTG & $15 / 2$ & scaffold_7:8897336:8897500:- & 165 & $5^{\prime}$ & -42.1 \\
\hline miR6281 & 21 & GTTAGAGATAGAGAGAGTGAG & $60 / 21$ & scaffold_8:277682:277841:+ & 160 & $5^{\prime}$ & -86 \\
\hline miR6282 & 23 & GTTGATCGATGTGGGATGTTACA & $8 / 1$ & scaffold_8:11190431:11190772:+ & 342 & $5^{\prime}$ & -93.3 \\
\hline miR6283 & 21 & CAAAAGGGGAGTGGGAAAATC & $33 / 2$ & scaffold_8:19627180:19627307:+ & 128 & $3^{\prime}$ & -64.9 \\
\hline miR6284 & 21 & TITGGACCATGGATGAAGATT & $5128 / 2$ & scaffold_8:20948100:20948196:+ & 97 & $3^{\prime}$ & -31.9 \\
\hline miR6285 & 22 & TAGTGAAGTTTGAATTAGGGCT & $2195 / 3$ & scaffold_8:16684630:16684710:- & 81 & $5^{\prime}$ & -38 \\
\hline miR6286 & 23 & TTTGAACCATTGGATCGTAGTTA & $8 / 1$ & scaffold_14:309411:309508:- & 98 & $5^{\prime}$ & -21.8 \\
\hline miR6287 & 21 & CAAGAAGTGGAAGTITTGGGC & $5 / 1$ & scaffold_1:17236128:17236204:- & 77 & $5^{\prime}$ & -31.3 \\
\hline miR6288 & 21 & GAAAATGACAAGTGGCTAGTT & $27 / 13$ & scaffold_2:18743450:18743549:+ & 100 & $3^{\prime}$ & -51.3 \\
\hline miR6289 & 21 & TCCTITGAATGGTTAGGCTCA & $7 / 1$ & scaffold_3:4077260:4077364:- & 105 & $3^{\prime}$ & -51.2 \\
\hline miR6290 & 23 & TGAATGAGTTCAGAGATCGTGTA & $17 / 12$ & scaffold_4:28016862:28016957:+ & 96 & $3^{\prime}$ & -18.7 \\
\hline miR6291a & 21 & СTTACCACATTTTATACCAT & $67 / 1$ & scaffold_4:8758152:8758281:- & 130 & $5^{\prime}$ & -66.31 \\
\hline miR6291b & 21 & СTTACCACATTTTATACCAT & $67 / 4$ & scaffold_7:5853383:5853533:+ & 151 & $5^{\prime}$ & -41.6 \\
\hline miR6292 & 21 & TATCTTTTAATCGTTAGATCA & $18 / 1$ & scaffold_4:11582347:11582421:- & 75 & $5^{\prime}$ & -29.99 \\
\hline miR6293 & 21 & TAAGAGGCTGATGACTAAAAC & $355 / 9$ & scaffold_5:2922263:2922370:+ & 107 & $5^{\prime}$ & -59.8 \\
\hline miR6294 & 21 & TGGTGTAGGCTAATCACAATC & $7 / 1$ & scaffold_5:18324006:18324209:+ & 204 & $3^{\prime}$ & -89.9 \\
\hline miR6295 & 21 & GAGGACAGAAGATGATTCAGC & $42 / 10$ & scaffold_6:25684504:25684833:+ & 330 & $3^{\prime}$ & -155.3 \\
\hline
\end{tabular}


Table 5 Novel miRNAs/new members of known miRNA families in perfect and imperfect libraries (Continued)

\begin{tabular}{|c|c|c|c|c|c|c|c|}
\hline miR6296 & 21 & TAAGGCCCTTAGATGAGACCC & $10 / 1$ & scaffold_6:28262446:28262576:+ & 131 & $3^{\prime}$ & -56 \\
\hline miR6297a & 23 & AATAATTITTCGTCGCGCAAAAT & $10 / 1$ & scaffold_8:6395625:6395769:+ & 145 & $3^{\prime}$ & -63.2 \\
\hline miR6297b & 23 & GATGTATTGTCGTCGCGCAAAGT & $11 / 11$ & scaffold_8:2802801:2802903:- & 103 & $3^{\prime}$ & -54.6 \\
\hline miR171a & 21 & TGATTGAGCCGTGCCAATATC & $1651 / 29$ & scaffold_3:16557250:16557364:+ & 115 & $3^{\prime}$ & -58.4 \\
\hline miR171c & 21 & TGATTGAGCCGTGCCAATATC & $1586 / 1$ & scaffold_3:21505898:21505996:- & 99 & $3^{\prime}$ & -46.3 \\
\hline miR171e & 21 & TTATTGAACCGGACCAATATC & $10 / 1$ & scaffold_3:16557258:16557354:- & 97 & $3^{\prime}$ & -39.8 \\
\hline miR171g & 21 & TGATTGAGCCGTGCCAATATC & $3634 / 3$ & scaffold_5:13607844:13607938:- & 95 & $3^{\prime}$ & -46.5 \\
\hline miR171h & 21 & TTGAGCCGCGTCAATATCTCC & $1141 / 43$ & scaffold_3:16525596:16525722:+ & 127 & $3^{\prime}$ & -44.32 \\
\hline miR319b & 22 & TAGCTGCCGAGTCATTCATCCA & $71 / 30$ & scaffold_5:11602974:11603095:- & 122 & $5^{\prime}$ & -49.26 \\
\hline miR394 & 21 & AAGCGTTTCTTACAGAGTTTA & $130 / 4$ & scaffold_1:32136105:32136248:- & 144 & $5^{\prime}$ & -65 \\
\hline miR477a & 21 & GTTGGGGGCTCTITTGGGACG & $161 / 28$ & scaffold_3:9747726:9747847:- & 122 & $3^{\prime}$ & -58.5 \\
\hline miR477b & 21 & GTTGGGGGCTCTTTTGGGACG & $161 / 28$ & scaffold_3:9752784:9752905:- & 122 & $3^{\prime}$ & -62.1 \\
\hline miR482a & 22 & TTTCCGAAACCTCCCATTCCAA & $1293 / 75$ & scaffold_1:29646062:29646181:+ & 120 & $3^{\prime}$ & -47.2 \\
\hline miR482b & 22 & СТТСССАААССТСССАТТССТА & $4677 / 518$ & scaffold_1:29648520:29648655:+ & 136 & $3^{\prime}$ & -55.5 \\
\hline miR482c & 20 & GGAATGGGCTGTTTGGGATG & $30342 / 30319$ & scaffold_3:10579287:10579407:+ & 121 & $5^{\prime}$ & -63.6 \\
\hline miR482d & 22 & СCTCCCATGCCACGCATTTCTA & $20734 / 3022$ & scaffold_8:10608388:10608531:- & 144 & $3^{\prime}$ & -59.3 \\
\hline miR482e & 22 & TTGCCTATTCCTCCСATGCCAA & $210 / 2$ & scaffold_1:29646743:29646870:+ & 128 & $3^{\prime}$ & -55 \\
\hline miR828 & 21 & TCATTCAGCAAGCAGCGTTA & $1491 / 1$ & scaffold_2:25971195:25971319:- & 125 & $3^{\prime}$ & -55.9 \\
\hline
\end{tabular}

buds. In addition, 61 potentially novel miRNAs/new members of known miRNA families were also identified, by the presence of mature miRNAs and corresponding miRNA*s in the sRNA libraries. Comparative analysis showed that six potentially novel miRNAs were differentially expressed between perfect and imperfect flower buds. Target predictions of the 13 differential miRNAs resulted in 212 target genes. GO annotation revealed that highly-ranked miRNA target genes were those implicated in the developmental process, regulation of transcription and response to stress. These findings, both computational and experimental, provide valuable information for further functional characterisation of miRNAs associated with pistil development in plants.

\section{Methods}

\section{Plant materials}

The frequency of imperfect flowers in Japanese apricot cultivar 'Daqiandi' is about 76\%. While the pistils of perfect flowers continued to develop, the pistils of imperfect flowers stopped developing in early December and ultimately disintegrated. The present study used these two

Table 6 miRNAs expressed differentially in perfect and imperfect libraries

\begin{tabular}{|c|c|c|c|c|c|c|c|c|c|}
\hline \multirow[t]{2}{*}{ Family } & \multirow[t]{2}{*}{ miRNA name } & \multicolumn{2}{|c|}{ Perfect } & \multicolumn{2}{|c|}{ Imperfect } & \multirow{2}{*}{$\begin{array}{l}\text { Fold-change } \\
\log 2(s 2 / s 1)\end{array}$} & \multirow[t]{2}{*}{ P-value } & \multirow[t]{2}{*}{ Mode } & \multirow[t]{2}{*}{ Sig-lable } \\
\hline & & Counts & Normalised & Counts & Normalised & & & & \\
\hline \multirow[t]{3}{*}{ MIR159 } & miR319 & 21 & 0.96 & 171 & 7.05 & 2.88 & $1.45 e-06$ & Up & $* *$ \\
\hline & miR319a & 121 & 5.50 & 1172 & 48.35 & 3.14 & 0 & Up & $* *$ \\
\hline & miR319e & 1 & 0.05 & 40 & 1.65 & 5.18 & 0 & Up & $* *$ \\
\hline MIR160 & miR160a & 110 & 5.00 & 808 & 33.33 & 2.74 & 0 & Up & $* *$ \\
\hline MIR393 & miR393a & 2 & 0.09 & 77 & 3.18 & 5.13 & $6.41 e-12$ & Up & $* *$ \\
\hline MIR394 & miR394a & 24 & 1.09 & 301 & 12.42 & 3.51 & $9.05 e-51$ & Up & $* *$ \\
\hline MIR395 & miR395a & 14 & 0.64 & 94 & 3.88 & 2.61 & $6.82 e-25$ & Up & $* *$ \\
\hline unknown & miR6274 & 60 & 2.73 & 0 & 0.01 & -8.09 & 0 & Down & $* *$ \\
\hline unknown & miR6268 & 178 & 8.10 & 66 & 2.72 & -1.57 & 0 & Down & $* *$ \\
\hline unknown & miR6295 & 0 & 0.01 & 42 & 1.73 & 7.44 & $1.97 e-37$ & Up & $* *$ \\
\hline MIR159 & miR319b & 0 & 0.01 & 71 & 2.93 & 8.19 & $4.14 e-99$ & Up & $* *$ \\
\hline MIR171 & miR171d & 0 & 0.01 & 2097 & 86.51 & 13.08 & 0 & Up & $* *$ \\
\hline MIR482 & miR482c & 30342 & 1380.12 & 0 & 0.01 & -17.07 & 0 & Down & $* *$ \\
\hline
\end{tabular}




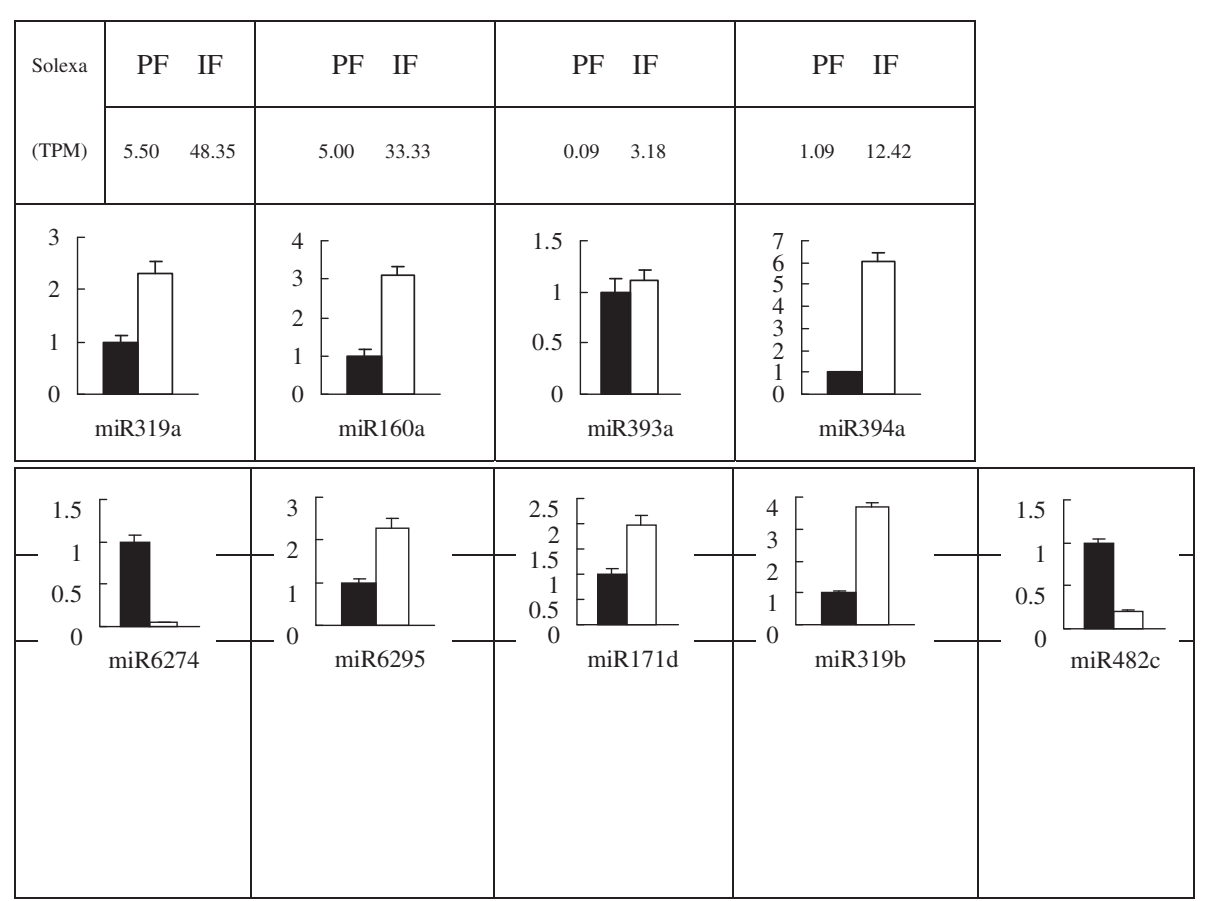

Figure 7 Expression confirmation of miRNAs in Japanese apricot derived from high throughput sequencing. Differentially expressed miRNAs expression detected by poly(A) qRT-PCR.

types of flower buds from this period, from 'Daqiandi' trees grown in the 'National Field Genebank for Japanese apricot' (Nanjing, Jiangsu Province, China). All the samples were collected and immediately frozen in liquid nitrogen and stored at $-80^{\circ} \mathrm{C}$.

\section{Small RNA library construction and high-throughput sequencing}

In order to construct small RNA libraries, small RNAs were extracted from perfect and imperfect flower buds using a method based on polyethylene glycol (PEG) precipitation combining CTAB buffer [67]. Two small RNA samples were sequenced by the Beijing Genomics Institute (BGI) (Shenzhen, Guangdong Province, China) using the high-throughput pyrosequencing technology developed by Solexa.

\section{Bioinformatics analysis of sequencing data}

The raw sequences were processed as described by Sunkar et al. [25]. Following removal of the vector sequences, modified sequences from $18 \mathrm{nt}$ to $30 \mathrm{nt}$ were used for further analyses. To begin with, rRNA, tRNA, snRNA, snoRNA and material containing the poly-A tail were removed from the sRNA sequences. The remaining sequences were compared with rice and Arabidopsis ncRNAs deposited in the NCBI GenBank and Rfam10.0 databases. Then, the unique sRNA sequences were used in a BLASTN search of the miRNA database. Only perfectly matched sequences were considered to be conserved miRNAs.

Potentially novel sequences were identified through alignment with the peach genome sequence on the GDR (http://www.rosaceae.org/species/prunus/peach). Candidate pre-miRNAs were identified by folding the flanking genome sequence of distinct miRNAs using MIREAP [55], followed by a prediction of secondary structure using mFold v3.5 [68]. The criteria chosen for stem-loop hairpins were those described by Meyers et al. and Wang et al. [42,55].

\section{Differential expression analyses of miRNAs related to pistil development}

The frequency of miRNAs in the two libraries was normalised to one million by the total number of miRNAs in each sample (normalised expression $=$ actual miRNA count/total count of clean reads*1,000,000). Following normalisation, if the miRNA gene expression of two samples was zero, then it was revised to 0.01; if the miRNA gene expression of two samples was less than 1 , owing to their too low expression and did not participate in analysis of differential expression.

The fold-change between treatment and control was calculated as: fold-change $=\log _{2}$ (imperfect/perfect). The $p$-value was calculated using the formula below $[69,70]$, where: N1 and N2 represent the total counts of clean reads of a given miRNA in the sRNA libraries of perfect 


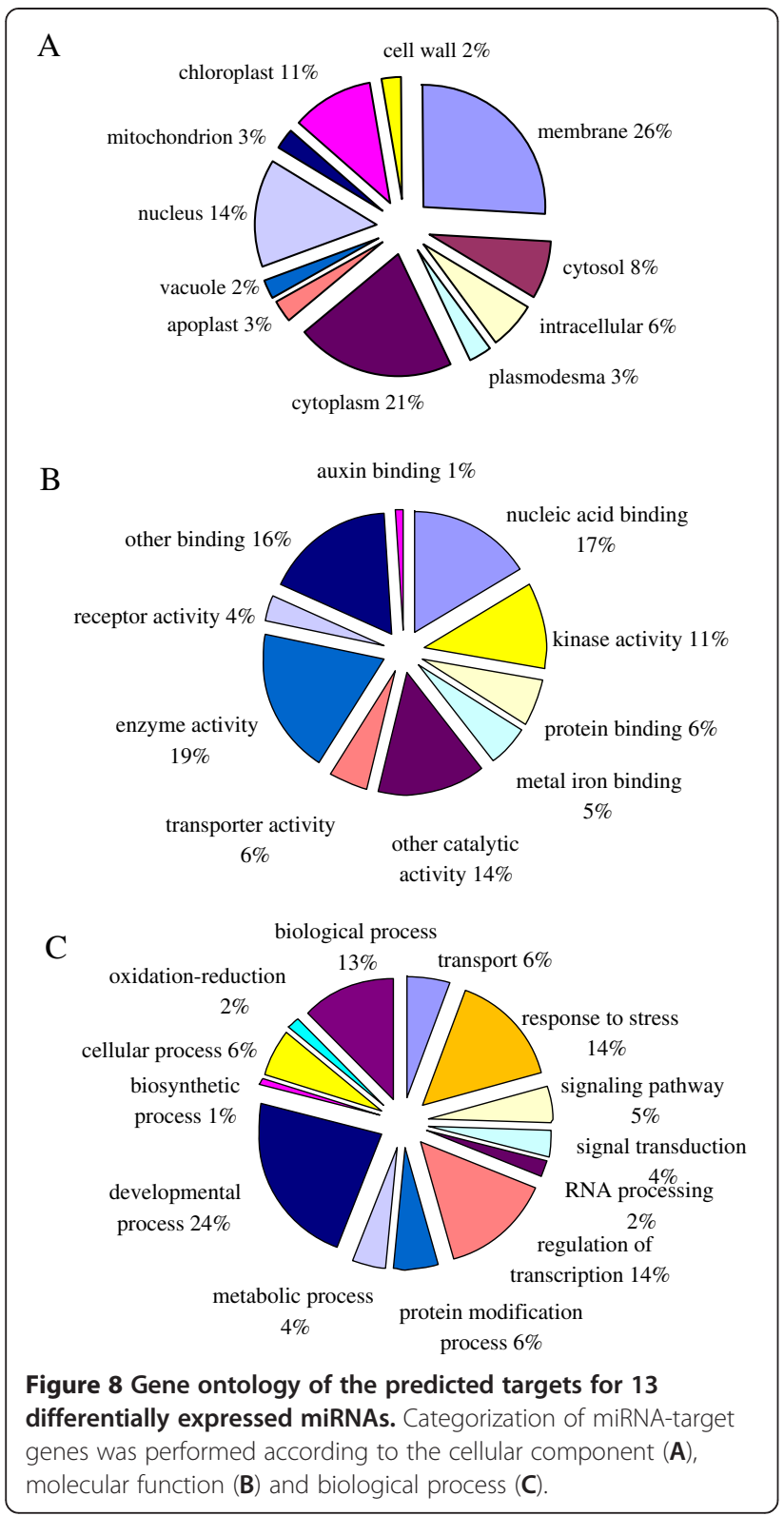

and imperfect flower bud samples, respectively; and $\mathrm{x}$ and $y$ represent the normalised expression levels of a given miRNA in the sRNA libraries of perfect and imperfect flower bud samples, respectively.

$$
\begin{aligned}
& p(x \mid y)=\left(\frac{N_{2}}{N_{1}}\right)^{y} \frac{(x+\gamma) !}{x ! \gamma !\left(1+\frac{N_{2}}{N_{1}}\right)^{(x+\gamma+1)}} \\
& C\left(\gamma \leq \gamma_{\min } \mid \mathrm{x}\right)=\sum_{\gamma=0}^{\gamma \leq \gamma_{\min }} p(\gamma \mid \mathrm{x}) \\
& D\left(\gamma \geq_{\max } \mid \mathrm{x}\right)=\sum_{\gamma \geq \gamma_{\max }}^{\infty} p(\gamma \mid \mathrm{x})
\end{aligned}
$$

\section{Prediction of potential target mRNAs for Japanese apricot} miRNAs

The rules used for target prediction were based on those suggested by Allen et al. [71] and Schwab et al. [72]. Putative Japanese apricot miRNAs were first blasted against the peach unigene database on the GDR (http://www.rosaceae.org/species/prunus/peach). BLASTN hits possessing less than four mismatches were chosen as candidate targets. BLASTX was then used to obtain their putative functions.

\section{Validation of miRNAs by poly(A)-tailed qRT-PCR}

The poly(A)-tailed qRT-PCR was carried out as previously reported, with a minor modifications $[67,73]$. This could not only detect the existence of Japanese apricot miRNAs, but also their expression trends in various organs and tissues. Small RNAs were extracted from Japanese apricot flower buds as described above and used in a $50-\mu \mathrm{l}$ reaction system for adding poly(A) tails with poly(A) polymerase (NEB, USA). Reverse transcription was performed using poly(A)-tailed small RNAs from Japanese apricot flower buds, such that $1 \mu \mathrm{g}$ of small RNA was reverse transcribed to cDNA using MLV reverse transcriptase (Promega, Madison, USA) and looped antisense primers [5'-CCAGTAGCGTATGATGAGCACA GAGTCTGAGATCACTCGTAGCGAGG-d(T) ${ }_{33}-\mathrm{V}(\mathrm{A} / \mathrm{C} /$ $\left.\mathrm{G}) \mathrm{N}(\mathrm{A} / \mathrm{C} / \mathrm{G} / \mathrm{T})-\mathrm{3}^{\prime}\right]$. According to the manufacturer's instructions, the mix was incubated at $37^{\circ} \mathrm{C}$ for 40 minutes. qPCR was performed using $\mathrm{SYBR}^{\circledR}$ Green Realtime PCR Master Mix (Toyobo, Osaka, Japan). A list of all the primers used is provided in Additional file 4. For each reaction, $1 \mu \mathrm{L}$ of diluted cDNA (equivalent to $100 \mathrm{pg}$ of total RNA) was mixed with $10 \mu \mathrm{L}$ of $2 X$ SYBR Green Reaction Mix (SYBR ${ }^{\circledR}$ Green qRT-PCR Master Mix, Takara). A final volume of $20 \mu \mathrm{L}$ was achieved by the addition of 5 pmol of the forward and the reverse primers. The conditions for the PCR amplification were as follows: polymerase activation at $95^{\circ} \mathrm{C}$ for 3 minutes, followed by 40 cycles of $95^{\circ} \mathrm{C}$ for 20 seconds, $60^{\circ} \mathrm{C}$ for 20 seconds and $72^{\circ} \mathrm{C}$ for 45 seconds. The fluorescence signal was measured once every $1^{\circ} \mathrm{C}$. Negative PCR controls (no cDNA template) were prepared, in order to detect possible contamination. The specificity of the primer amplicons was tested by the analysis of a melting curve. The CT values were converted into relative copy numbers using a standard curve [44]. The $5 \mathrm{~S}$ rRNA was used as a reference gene in the qPCR detection of miRNAs in Arabidopsis [56,74]. The data was analysed with an $\mathrm{R}^{2}$ $>0.998$ using the LinRegPCR program [75].

\section{Additional files}

Additional file 1: The predicted hairpin structures of all the potentially novel miRNAs/new members of known miRNA families' precursors. The red lightened sequences are mature miRNAs. 
Additional file 2: Alignments of all reads from each hairpin of potentially novel miRNAs/new members of known miRNA families. Additional file 3: The potential targets of differentially expressed miRNAs.

Additional file 4: The primers designed for qRT-PCR.

\section{Competing interests}

The authors declare that they have no competing interest.

\section{Authors' contributions}

$\mathrm{TS}, \mathrm{XL}$ and $\mathrm{WZ}$ were responsible for generating the sRNA data and interpreting the results. TS and $X L$ carried out the $\mathrm{GRT}$-PCR experiments. TS drafted the manuscript. ZZ, LW and ZG participated in the research design and statistical analyses. ZG proposed and supervised the research. All authors read and approved the final manuscript.

\section{Acknowledgements}

We gratefully acknowledge support of this research by the Special Fund for Agro-scientific Research in the Public Interest of the Ministry of Agriculture of China (201003058), grants from the National Science Foundation of China (31101526) and the Natural Science Foundation of Jiangsu Province (BK2011642), and a project funded by the Priority Academic Program Development of Jiangsu Higher Education Institutions (PAPD)

Received: 21 November 2011 Accepted: 25 July 2012 Published: 3 August 2012

\section{References}

1. Chu MY: China fruit records-Mei (in Chinese). Beijing: China Forestry; 1999.

2. Gao Z, Wang S, Zhang Z: Comparative study on flower and fruit characteristics of 29 varieties in Japanese apricot (Prunus mume Sieb. et Zucc.). Jiangsu Agri Sci 2006, 6:231-233

3. Hou J, Gao Z, Wang S, Zhang Z, Chen S, Ando T, Zhang J, Wang X: Isolation and characterization of an AGAMOUS homologue PmAG from the Japanese Apricot (Prunus mume Sieb. et Zucc.). Plant Mol Biol Rep 2011. 29:473-480.

4. Wang S, Gao Z, Zhang Z, Xu J, Hou J: Comparison of the contents of nitrogen, phosphorus and potassium between perfect and imperfect flowers in Japanese apricot (Prunus mume). J Fruit Sci 2009, 26:564-567.

5. Montgomery TA, Howell MD, Cuperus JT, Li D, Hansen JE, Alexander AL, Chapman EJ, Fahlgren N, Allen E, Carrington JC: Specificity of ARGONAUTE7-miR390 interaction and dual functionality in TAS3 transacting siRNA formation. Cell 2008, 133:128-141.

6. Zhu QH, Helliwell CA: Regulation of flowering time and floral patterning by miR172. J Exp Bot 2011, 62:487.

7. Nag A, Jack T: Sculpting the flower; the role of microRNAs in flowe development. Curr Top Dev Biol 2010, 91:349-378.

8. Liu X, Huang J, Wang Y, Khanna K, Xie Z, Owen HA, Zhao D: The role of floral organs in carpels, an Arabidopsis loss-of-function mutation in MicroRNA160a, in organogenesis and the mechanism regulating its expression. Plant J 2010, 62:416-428.

9. Lee H, Yoo SJ, Lee JH, Kim W, Yoo SK, Fitzgerald H, Carrington JC, Ahn JH: Genetic framework for flowering-time regulation by ambient temperature-responsive miRNAs in Arabidopsis. Nucleic Acids Res 2010, 38:3081-3093.

10. Zhang Y, Cao G, Qu $\sqcup$, Gu H: Involvement of an R2R3-MYB transcription factor gene AtMYB118 in embryogenesis in Arabidopsis. Plant Cell Rep 2009, 28:337-346

11. Wang J, Czech B, Weigel D: miR156-regulated SPL transcription factors define an endogenous flowering pathway in Arabidopsis thaliana. Cell 2009, 138:738-749

12. Amiteye S, Corral JM, Vogel H, Sharbel TF: Analysis of conserved microRNAs in floral tissues of sexual and apomictic Boechera species. BMC Genomics 2011, 12:500.

13. Wang S: Preliminary studies on differences of related characteristics between perfect flower and imperfect flower and protemics in Japanese apricot. Nanjing: Nanjing Agricultural University; 2008.

14. Carthew RW, Sontheimer EJ: Origins and mechanisms of miRNAs and siRNAs. Cell 2009, 136:642-655.
15. Mallory AC, Vaucheret $\mathrm{H}$ : Functions of microRNAs and related small RNAs in plants. Nat Genet 2006, 38:S31-S37.

16. Chen C, Ridzon DA, Broomer AJ, Zhou Z, Lee DH, Nguyen JT, Barbisin M, Xu NL, Mahuvakar VR, Andersen MR: Real-time quantification of microRNAs by stem-loop RT-PCR. Nucleic Acids Res 2005, 33:e179.

17. Jones-Rhoades MW, Bartel DP, Barte B: MicroRNAs and their regulatory roles in plants. Annu Rev Plant Biol 2006, 57:19-53.

18. Bushati N Cohen SM: MicroRNA functions. Annu Rev Cell Dev Biol 2007. 23:175-205

19. Mette MF, Winden J, Matzke M, Matzke AJM: Short RNAs can identify new candidate transposable element families in Arabidopsis. Plant Physiol 2002, 130:6-9.

20. Llave C, Xie Z, Kasschau KD, Carrington JC: Cleavage of scarecrow-like mRNA targets directed by a class of Arabidopsis miRNA. Science 2002, 297:2053.

21. Zhang B, Pan X, Cobb GP, Anderson TA: Plant microRNA: a small regulatory molecule with big impact. Dev Biol 2006, 289:3-16.

22. Jones-Rhoades MW, Bartel DP, Bartel B: MicroRNAs and their regulatory roles in plants. Annu Rev Plant Biol 2006, 57:19-53.

23. Rubio-Somoza I, Weigel D: MicroRNA networks and developmenta plasticity in plants. Trends Plant Sci 2011, 16:258-264.

24. An FM, Hsiao SR, Chan MT: Sequencing-based approaches reveal low ambient temperature-responsive and tissue-specific microRNAs in Phalaenopsis orchid. PLOS One 2011, 6:e18937.

25. Sunkar $R$, Jagadeeswaran $G$ : In silico identification of conserved microRNAs in large number of diverse plant species. BMC Plant Biol 2008, 8:37.

26. Song C, Fang J, Li X, Liu H, Chao CT: Identification and characterization of 27 conserved microRNAs in citrus. Planta 2009, 230:671-685.

27. Rajagopalan R, Vaucheret $H$, Trejo J, Bartel DP: A diverse and evolutionarily fluid set of microRNAs in Arabidopsis thaliana. Genes Dev 2006 20:3407-3425

28. Fahlgren N, Howell MD, Kasschau KD, Chapman EJ, Sullivan CM, Cumbie JS, Givan SA, Law TF, Grant SR, Dangl JL: High-throughput sequencing of Arabidopsis microRNAs: evidence for frequent birth and death of MIRNA genes. Plos One 2007, 2:e219.

29. Nobuta K, Venu R, Lu C, Beló A, Vemaraju K, Kulkarni K, Wang W, Pillay M, Green PJ, Wang G: An expression atlas of rice mRNAs and small RNAs. Nat Biotechnol 2007, 25:473-477.

30. Zhou M, Gu L, Li P, Song X, Wei L, Chen Z, Cao X: Degradome sequencing reveals endogenous small RNA targets in rice (Oryza sativa L. ssp. indica). Front Biol 2010, 5:67-90.

31. Barakat A, Wall P, DiLoreto S: Conservation and divergence of microRNAs in Populus. BMC Genomics 2007, 8:481.

32. Klevebring D, Street N, Fahlgren N, Kasschau K, Carrington J, Lundeberg J, Jansson S: Genome-wide profiling of Populus small RNAs. BMC Genomics 2009, 10:620.

33. Lu YD, Gan QH, Chi XY, Qin S: Identification and characterization of microRNAs and their targets in grapevine (Vitis vinifera). Agr Sci China 2008, 7:929-943

34. Zhao CZ, Xia H, Frazier TP, Yao YY, Bi YP, Li AQ, Li MJ, Li CS, Zhang BH, Wang $X J$ : Deep sequencing identifies novel and conserved microRNAs in peanuts (Arachis hypogaea L.). BMC Plant Biol 2010, 10:3.

35. Xu Q, Liu Y, Zhu A, Wu X, Ye J, Yu K, Guo W, Deng X: Discovery and comparative profiling of microRNAs in a sweet orange red-flesh mutant and its wild type. BMC Genomics 2010, 11:246.

36. Song C, Wang C, Zhang C, Korir N, Yu H, Ma Z, Fang J: Deep sequencing discovery of novel and conserved microRNAs in trifoliate orange (Citrus trifoliata). BMC Genomics 2010, 11:431

37. Wang $\mathrm{T}$, Chen $\mathrm{L}$, Zhao $\mathrm{M}$, Tian $\mathrm{Q}$, Zhang $\mathrm{W}-\mathrm{H}$ : Identification of drought responsive microRNAs in Medicago truncatula by genome-wide highthroughput sequencing. BMC Genomics 2011, 12:367.

38. Szittya G, Moxon S, Santos DM, Jing R, Fevereiro MPS, Moulton V, Dalmay T: High-throughput sequencing of Medicago truncatula short RNAs identifies eight new miRNA families. BMC Genomics 2008, 9:593.

39. Song $Q$, Liu Y, Hu X, Zhang W, Ma B, Chen S, Zhang J: Identification of miRNAs and their target genes in developing soybean seeds by deep sequencing. BMC Plant Biol 2011, 11:5.

40. Martínez G, Forment J, Llave C, Pallás V, Gómez G: High-throughput sequencing, characterization and detection of new and conserved cucumber miRNAs. PLoS One 2011, 6:e19523. 
41. Yang Y, Chen X, Chen J, Xu H, Li J, Zhang Z: Differential miRNA expression in Rehmannia glutinosa plants subjected to continuous cropping. BMC Plant Biol 2011, 11:53.

42. Meyers BC, Axtell MJ, Bartel B, Bartel DP, Baulcombe D, Bowman JL, Cao X, Carrington JC, Chen X, Green PJ, et al: Criteria for annotation of plant microRNAs. Plant Cell 2008, 20:3186-3190.

43. Sunkar R, Zhu JK: Novel and stress-regulated microRNAs and other small RNAs from Arabidopsis. Plant Cell 2004, 16:2001.

44. Jones-Rhoades MW, Bartel DP: Computational identification of plant microRNAs and their targets, including a stress-induced miRNA. Mol Cell 2004, 14:787-799.

45. Bonnet E, Wuyts J, Rouzé P, Van de Peer Y: Detection of 91 potential conserved plant microRNAs in Arabidopsis thaliana and Oryza sativa identifies important target genes. Proc Natl Acad Sci USA 2004, 101:11511-11516

46. Zhang B, Pan X, Wang Q, Cobb GP, Anderson TA: Identification and characterization of new plant microRNAs using EST analysis. Cell Res 2005, 15:336-360.

47. Yu H, Song C, Jia Q, Wang C, Li F, Nicholas KK, Zhang X, Fang J: Computational identification of microRNAs in apple expressed sequence tags and validation of their precise sequences by miR-RACE. Physiol Plant 2011, 141:56-70

48. Moxon S, Jing R, Szittya G, Schwach F, Rusholme Pilcher RL, Moulton V, Dalmay T: Deep sequencing of tomato short RNAs identifies microRNAs targeting genes involved in fruit ripening. Genome Res 2008, 18:1602.

49. Pang M, Woodward AW, Agarwal V, Guan X, Ha M, Ramachandran V, Chen $X$, Triplett BA, Stelly DM, Chen ZJ: Genome-wide analysis reveals rapid and dynamic changes in miRNA and siRNA sequence and expression during ovule and fiber development in allotetraploid cotton (Gossypium hirsutum L.). Genome Biol 2009, 10:R122.

50. Huang S, Li R, Zhang Z, Li L, Gu X, Fan W, Lucas WJ, Wang X, Xie B, Ni P: The genome of the cucumber, Cucumis sativus L. Nat Genet 2009, 41:1275-1281

51. Xu M, Liu Q, Nisbet AJ, Cai X, Yan C, Lin R, Yuan Z, Song H, He X, Zhu X: Identification and characterization of microRNAs in Clonorchis sinensis of human health significance. BMC Genomics 2010, 11:521.

52. Bartel DP: MicroRNAs: genomics, biogenesis, mechanism, and function. Cell 2004, 116:281-297.

53. Yang X, Zhang H, Li L: Global analysis of gene-level microRNA expression in Arabidopsis using deep sequencing data. Genomics 2011, 98:40-46.

54. Wang Y, Itaya A, Zhong X, Wu Y, Zhang J, van der Knaap E, Olmstead R, Qi $Y$, Ding B: Function and evolution of a microRNA that regulates a CaZ +-ATPase and triggers the formation of phased small interfering RNAs in tomato reproductive growth. Plant Cell 2011, 23:3185-3203.

55. Wang L, Liu H, Li D, Chen H: Identification and characterization of maize microRNAs involved in the very early stage of seed germination. BMC Genomics 2011, 12:154.

56. Wang C, Wang X, Kibet NK, Song C, Zhang C, Li X, Han J, Fang J: Deep sequencing of grapevine flower and berry short RNA library for discovery of novel microRNAs and validation of precise sequences of grapevine microRNAs deposited in miRBase. Physiol Plant 2011, 143:64-81.

57. Pantaleo V, Szittya G, Moxon S, Miozzi L, Moulton V, Dalmay T, Burgyan J: Identification of grapevine microRNAs and their targets using highthroughput sequencing and degradome analysis. Plant J 2010, 62:960-976.

58. Zhao $L$, Kim YJ, Dinh $T T$, Chen X: miR172 regulates stem cell fate and defines the inner boundary of APETALA3 and PISTILLATA expression domain in Arabidopsis floral meristems. Plant J 2007, 51:840-849.

59. Ji L, Liu X, Yan J, Wang W, Yumul RE, Kim YJ, Dinh T, Liu J, Cui X, Zheng B, et al: ARGONAUTE10 and ARGONAUTE1 regulate the termination of floral stem cells through two microRNAs in Arabidopsis. PLoS Genet 2011, 7:e1001358.

60. Reinhart BJ, Weinstein EG, Rhoades MW, Bartel B, Bartel DP: MicroRNAs in plants. Genes Dev 2002, 16:1616-1626.

61. Licausi F, Weits DA, Pant BD, Scheible WR, Geigenberger P, Van Dongen JT: Hypoxia responsive gene expression is mediated by various subsets of transcription factors and miRNAs that are determined by the actual oxygen availability. New Phytol 2011, 190:442-456.
62. Earley K, Smith M, Weber R, Gregory B, Poethig R: An endogenous F-box protein regulates ARGONAUTE1 in Arabidopsis thaliana. Silence 2010, $1: 1-10$.

63. Wang $L$, Hua D, He J, Duan $Y$, Chen Z, Hong X, Gong Z: Auxin Response Factor2 (ARF2) and its regulated homeodomain gene HB33 mediate abscisic acid response in Arabidopsis. PLoS Genet 2011, 7:e1002172.

64. Lim PO, Lee IC, Kim J, Kim HJ, Ryu JS, Woo HR, Nam HG: Auxin response factor 2 (ARF2) plays a major role in regulating auxin-mediated leaf longevity. J Exp Bot 2010, 61:1419-1430

65. Ellis CM, Nagpal P, Young JC, Hagen G, Guilfoyle TJ, Reed JW: AUXIN RESPONSE FACTOR1 and AUXIN RESPONSE FACTOR2 regulate senescence and floral organ abscission in Arabidopsis thaliana. Development 2005, 132:4563-4574.

66. Palatnik JF, Wollmann H, Schommer C, Schwab R, Boisbouvier J, Rodriguez R, Warthmann N, Allen E, Dezulian T, Huson D: Sequence and expression differences underlie functional specialization of Arabidopsis microRNAs miR159 and miR319. Dev Cell 2007, 13:115-125.

67. Wang X, Xiong A, Yao Q, Zhang Z, Qiao Y: Direct isolation of high-quality low molecular weight RNA of pear peel from the extraction mixture containing nucleic acid. Mol Biotechnol 2009, 44:61-65.

68. Zuker M: Mfold web server for nucleic acid folding and hybridization prediction. Nucleic Acids Res 2003, 31:3406-3415.

69. Jiang P, Wu H, Wang W, Ma W, Sun X, Lu Z: MiPred: classification of real and pseudo microRNA precursors using random forest prediction model with combined features. Nucleic Acids Res 2007, 35:W339-W344.

70. Li G, Li Y, Li X, Ning X, Li M, Yang G: MicroRNA identity and abundance in developing swine adipose tissue as determined by Solexa sequencing. J Cell Biochem 2011, 112:1318-1328.

71. Allen E, Xie Z, Gustafson AM, Carrington JC: microRNA-directed phasing during trans-acting siRNA biogenesis in plants. Cell 2005, 121:207-221.

72. Schwab R, Palatnik JF, Riester M, Schommer C, Schmid M, Weigel D: Specific effects of microRNAs on the plant transcriptome. Dev Cell 2005, 8:517-527.

73. Fujii H, Chiou TJ, Lin SI, Aung K, Zhu JK: A miRNA involved in phosphatestarvation response in Arabidopsis. Curr Biol 2005, 15:2038-2043.

74. Shi $R$, Chiang VL: Facile means for quantifying microRNA expression by real-time PCR. Biotechniques 2005, 39:519-525.

75. Ramakers C, Ruijter JM, Deprez RHL, Moorman AFM: Assumption-free analysis of quantitative real-time polymerase chain reaction (PCR) data. Neurosci Lett 2003, 339:62-66.

doi:10.1186/1471-2164-13-371

Cite this article as: Gao et al:: High-throughput sequencing of small RNAs and analysis of differentially expressed microRNAs associated with pistil development in Japanese apricot. BMC Genomics 2012 13:371.

\section{Submit your next manuscript to BioMed Central and take full advantage of:}

- Convenient online submission

- Thorough peer review

- No space constraints or color figure charges

- Immediate publication on acceptance

- Inclusion in PubMed, CAS, Scopus and Google Scholar

- Research which is freely available for redistribution 